\title{
Functional Evaluation in Inherited Retinal Disease
}

2

3 Malena Daich Varela, ${ }^{1,2}$ Michalis Georgiou, ${ }^{1,2,3}$ Shaima A. Hashem, ${ }^{1,2}$ Richard G. Weleber, ${ }^{4}$ Michel Michaelides ${ }^{1,2}$

4

51 UCL Institute of Ophthalmology, University College London, London, United Kingdom.

62 Moorfields Eye Hospital, London, United Kingdom.

$7{ }^{3}$ Department of Ophthalmology, Jones Eye Institute, University of Arkansas for Medical Sciences, Little Rock, Arkansas.

$8{ }^{4}$ Casey Eye Institute, Oregon Health \& Science University, Portland, Oregon, USA

9

10

11 Corresponding author:

12 Professor Michel Michaelides,

13 UCL Institute of Ophthalmology,

14 11-43 Bath St, EC1V 9EL.

15 London, United Kingdom.

16 michel.michaelides@ucl.ac.uk

17

18 Word count: $\mathbf{X X X X}$ words 


\section{Abstract}

20

21 Functional assessments are a fundamental part of the clinical evaluation of patients with inherited retinal diseases (IRD).

22 Their importance and impact have become increasingly notable given the significant breadth and number of clinical trials

23 and studies investigating multiple avenues of intervention across a wide range of IRD, including gene, pharmacological and

24 cellular therapies. Moreover, the fact that many clinical trials are reporting improvements in vision, rather than the previously

25 anticipated structural stability/slowing of degeneration, makes functional evaluation of primary relevance. In this review, we

26 will describe a range of methods employed to characterise retinal function and functional vision, beginning with tests variably

27 included in the clinic, such as visual acuity (VA), electrophysiological assessment and colour discrimination; and then

28 discuss assessments often reserved for clinical trials / research studies such as photoaversion testing, full-field static

29 perimetry and microperimetry, and vision-guided mobility testing; discussing perimetry in greatest detail given it is commonly

30 a primary outcome metric. We will focus on how these tests can help diagnose and monitor particular genotypes - also

31 noting their limitations/challenges, exploring analytical methodologies for better exploiting the functional measurements, as

32 well as how they facilitate patient inclusion and stratification in clinical trials and serve as outcome measures. 
34 Inherited retinal diseases (IRD) are a complex group of conditions with a wide genotypic and phenotypic spectrum. ${ }^{1-4}$

35 Detailed functional assessment is valuable in the diagnosis and monitoring of IRD, in both clinical and research settings. A

36 wide range of tests and devices have been developed to record and quantify retinal function and functional vision, which

37 vary in their degree of objective measurement and subjective patient response, all having significant benefits and limitations.

38 In these regards, functional characterisation is similar to structural characterisation, in that for both a 'multi-modal' evaluation

39 is most informative. The degree of change in any of these measurements that is universally agreed to be clinically

40 meaningful remains to be established; although for inexorably progressive IRD, any change that is greater than test-retest

41 variability for the metric may be clinically meaningful. Functional testing, whilst subject to concomitant ocular disorders such

42 as media opacity, myopic retinopathy and aging, significantly contributes to our understanding of disease pathophysiology,

43 informs advice on prognosis, assists monitoring the impact of interventions, and increasingly underpins clinical trial

44 endpoints. An overview of the functional assessments included in this review is shown in Tables 1 and 2.

45

\section{Best Corrected Visual Acuity (BCVA)}

47 Visual acuity (VA) represents the ocular spatial resolving capacity. ${ }^{5}$ Quantification of VA is usually the first assessment in

48 clinic, and by far the most commonly performed. Knowing the VA and the BCVA of an individual is essential in the evaluation

49 of the function and integrity of the visual system. The first and most widespread chart was developed by Snellen in $1862 .{ }^{5}$

50 However, it has an imprecise scoring method that uses lines instead of letters and lacks standardization, leading to

51 difficulties in statistical analysis. ${ }^{6}$ Hence the current gold standard is the retro-illuminated logarithm of the minimum angle

52 of resolution (LogMAR) chart, following the Early Treatment Diabetic Retinopathy Study (ETDRS) optotype, ${ }^{7}$ which has high

53 repeatability, and is therefore the method of choice in clinical trials. ${ }^{8}$ Other commonly used methods to assess VA include 
54 the Tumbling E-chart, Landolt C optotypes (both for illiterate or non-Latin language speaking patients and children), and

55 those specifically tailored for children such as Kay Pictures, Lea Symbols and Allen Figures. ${ }^{9}$

56

BCVA is typically reduced early in cone dysfunction syndromes (e.g. achromatopsia (ACHM)), cone and cone-rod dystrophies (COD/CORD), macular dystrophies (MD) and early-onset severe retinal dystrophy/Leber congenital amaurosis (EOSRD/LCA), but is often preserved until late stages in rod-cone dystrophies (RCD).,10-12 BCVA has been shown to significantly correlate with the width and integrity of the ellipsoid zone (EZ) on optical coherence tomography (OCT), ${ }^{13}$ as well as with visual field (VF). ${ }^{14,15}$ However, BCVA can show notable disconnect with structural measures (both better or worse respectively, than predicted from anatomy alone), including in certain genotypes such as RDH12 and CEP290, and also in cone density measured with adaptive optics (AO) imaging can be up to $60 \%$ decreased and yet acuity remains normal - highlighting the redundancy in the visual system and potentially boding well for cell replacement strategies. ${ }^{16}$ BCVA is an outcome measure included in all IRD trials.

\section{Low Luminance VA (LLVA)}

LLVA can be measured by placing a 2.0 log unit neutral density filter over the patient's best correction or over the ETDRS chart, while the latter is read. ${ }^{17}$ Other options include using a U23 NoIR 4\% transmission filter to simulate mesopic conditions. ${ }^{18}$ Patients with RCD have difficulties in dim environments and have reduced LLVA from the earliest stages of disease. ${ }^{19}$ Consequently, changes in LLVA are secondary outcome measures in gene therapy trials for the following RCDs: USH2A (NCT03780257), RHO (NCT04123626), CHM (NCT03496012) and RPGR (NCT03252847). The measurement of LLVA is an inexpensive and simple procedure, although more data regarding its correlation with other parameters are needed. 


\section{Contrast Sensitivity}

Reduced contrast sensitivity (CS) is a frequent symptom in IRD - significantly impairing central vision; even in those with normal or near-normal BCVA. ${ }^{20,21}$ Multiple methods have been used to assess CS, but Pelli-Robson (PR) charts ${ }^{20}$ are currently the most frequently used, both in clinical and research settings. ${ }^{21,22}$ However, the PR chart has relatively sparse spatial frequencies and stimulus contrast, which may lead to imprecision. Newer computer-based methods to evaluate CS (e.g. the Quick Contrast Sensitivity Function test and photoreceptor-specific temporal contrast sensitivity) are continuously evolving, with early evidence suggesting higher resolution assessments and thereby more capability to detect change over time. ${ }^{23-26}$

A decrease in CS has been documented in patients with $\mathrm{RCD},{ }^{27} \mathrm{ACHM},{ }^{4,10,22}$ and $\mathrm{CORD} .{ }^{28}$ Higher spatial frequencies (6.0 to 18.0) are usually more severely affected, as reported in individuals with USH2A-RCD, $A B C A 4$ retinopathy and $B E S T 1$ maculopathy. ${ }^{21,29,30}$ An association between mean retinal sensitivity (MS) and CS has been reported in patients with RCD and $\mathrm{ACHM}{ }^{22,31}$ Moreover, CS was significantly associated with reading speed in patients with $A B C A 4$ retinopathy and $\mathrm{RCD} .{ }^{27,28} \mathrm{CS}$ assessment is an easy and clinically important method to monitor visual function, being currently a secondary outcome measure in many gene therapy trials for the following RCDs: PDE6A (NCT04611503), RLBP1 (NCT03374657) and RPGR (NCT04671433); as well as in multiple pharmacological trials for Stargardt disease (STGD; ABCA4). ${ }^{1}$

\section{Colour Vision}

Colour vision (CV) defects are typically observed at an early stage with CORD, ACHM and cone dysfunction syndromes. 3,10 Individuals with RCD may also report early issues with CV; ${ }^{32,33}$ and certainly at later stages of disease as cone function becomes compromised. CV can be assessed by a wide range of tests. The most commonly used in the clinic is one of the oldest: the Ishihara pseudoisochromatic plates. ${ }^{34}$ However, whilst easy to use, it lacks evaluation of the tritan axis. ${ }^{34}$ HardyRand-Rittler pseudoisochromatic plates are as easy to administer and assess discrimination along all 3 colour axes. ${ }^{35}$ 
Another option are the Farnsworth-Munsell tests, where the patient sorts coloured caps according to their chromaticity. The 100-Hue version consists of 85 caps and now also exists as a computer-based test; while the D15 has only 15 caps (with the PV-16 being a low vision version with enlarged caps). ${ }^{36}$ These tests are more challenging to administer and more time consuming, but especially useful when assessing and monitoring acquired CV defects. ${ }^{36}$ Computerised systems are primarily employed in research and offer a quantitative and more comprehensive characterisation of colour discrimination. The Cambridge Colour Test (CCT) is the first popular computer-based test. ${ }^{37}$ It consists of pseudoisochromatic plates at decreasing luminance levels and also has a low vision version (IvvCCT), suitable for visually impaired individuals. ${ }^{38}$ Other computerized tests available are the Rabin Cone Contrast Test and the Universal Colour Discrimination Test (UCDT), the latter being suitable for individuals with low vision. ${ }^{18,38}$

CV testing helps to discriminate between cone dysfunction syndromes, including between complete and incomplete $\mathrm{ACHM}$ - one of the features of the latter being residual colour perception. ${ }^{4}$ In addition, tests probing the tritan axis, including that created by Berson et al. are valuable in helping to identify males with blue cone monochromacy. ${ }^{39}$ By detailed testing of colour discrimination in individuals with IRD, we can infer how different cone classes are affected and this can help with the differential diagnosis and suggest a genetic basis. ${ }^{40,41} \mathrm{CV}$ is a secondary outcome measure in on-going $\mathrm{ACHM}$ gene therapy trials, including NCT03001310 and NCT02599922 (both CNGB3), and also NCT03758404 and NCT02935517 (both CNGA3).

\section{Visual Field (VF) and Retinal Sensitivity}

In 1927, Traquair first described the VF as "an island of vision in a sea of darkness". ${ }^{2}$ Loss of peripheral VF as occurs in early forms of RCD results in symptoms such as tripping, bumping into people/obstacles, struggling to find objects, or difficulty navigating in dim or crowded/unfamiliar environments. In contrast, loss of central VF in COD/CORD, MD and EOSRD/LCA, usually leads to difficulties in recognizing faces, reading signs and identifying objects. 
VF evaluation, as performed using kinetic and static perimetry, has evolved significantly over the last two decades.

121 Kinetic VF testing has been used to monitor progression in patients with RCD and Usher syndrome - with semi-automated

122 kinetic perimetry (SKP) being more frequently employed. ${ }^{43-48}$ However, there is no consensus or standard method of

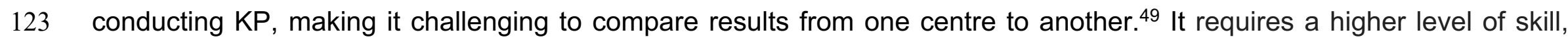

124 greater training, knowledge about expected field defects in specific diseases, and experience. KP has a higher test-retest

125 variability (up to 20-30\%) and its quality and efficiency can vary substantially even within the same clinical centre, from one

126 examination to another, as well as due to patient cooperation. ${ }^{45,49}$ Whilst test-retest variability is less for SKP, the major

127 drawback of all KP remains that, because the shape and height of the hill of vision depends upon the existing pathology for

128 the individual patient, it is not possible to fully automate it for all clinical situations. ${ }^{49} \mathrm{KP}$ is a valuable tool to define sharp

129 borders of blind areas, however it is less able to detect mild slopes or transitions between seeing and unseeing parts, or to

130 distinguish shallow islands of remaining sensitivity.

131 Semi-automated static perimetry (SP) by Octopus 900 is a robust method to comprehensively evaluate retinal

132 sensitivity/visual field integrity and has been applied in a broad range of genotypes in both adults and children, including

133 RPE65, ABCA4, RPGR and USH2A. ${ }^{50-53}$ It also has lesser dependency than kinetic testing on the technician's expertise,

134 and less inherent test-retest variability. A major advantage of static over KP is the availability of parameters that evaluate

135 the reliability and validity of patient test responses, such as the frequency of false positive and false negative responses,

136 and the quantification of a reliability factor (RF). Variability and inconsistencies between test sessions and among test

137 subjects can be reduced and validity of testing increased by specific instructions read to the patient by the perimetrist before

138 each test as to how to respond to the test stimulus presentations. ${ }^{54}$ Static testing is better than kinetic testing at detecting

139 and defining gradual changes of either lesser or greater sensitivity and isolated regions of residual sensitivity in advanced

140 disease. ${ }^{49}$ The Humphrey perimetry has been extensively used for clinical studies and trials for glaucoma and to a lesser

141 extent, mostly in the past, for IRD. The fast integrated SITA Standard thresholding algorithm available on the Humphrey 
142 perimeter is based on frequency of seeing curves for glaucoma and is, thus, sub-optimal for retinal diseases. ${ }^{55}$ The normal 4-2-1 strategy on the Humphrey takes much longer and is, therefore not suited for full-field static testing. The Octopus 900 perimeter, using the fast German Adaptive Thresholding Estimation (GATE) algorithm, 56,57 is currently the most robust and optimal system for static testing the entire visual field of patients with IRD. The GATE algorithm is as fast as the SITA Standard and has a validity and precision comparable to the normal 4-2-1 strategy. Octopus 900 perimetry using the GATE strategy has become the most commonly used device for clinical studies and treatment trials for IRD. ${ }^{15,55,58,59}$ The Octopus system allows (i) use of custom color test targets, (ii) a validated, retina-specific optimized testing strategy to be employed, i.e., GATE, and arguably most importantly (iii) exportation of all raw retinal sensitivity data, which can then be comprehensively and robustly analyzed, using Visual Field Modelling and Analysis (VFMA) methodology

151 (Figure 1), ${ }^{60}$ from which topographic displays and hill-of-vision volumetric outputs can be derived; including the total hill-of152 vision ( $\left.\mathrm{V}_{\text {Tот }}\right)$ or any subset e.g. the central 30 degree field of vision $\left(\mathrm{V}_{30}\right){ }^{52}$ These volumetric analyses afforded by $\mathrm{VFMA}$ 153 can be applied equally as well to VF data obtained from microperimetry, ${ }^{22,61,62}$ potentially allowing game-changing state-of154 the-art retinal function evaluation in IRD and other retinal diseases, ${ }^{63}$ and enabling incorporation of all data in a non-biased 155 fashion, truly representing the full impact of disease natural history or treatment effect. Assessment of retinal sensitivity 156 using VFMA with creation of volumetric endpoints, such as $\mathrm{V}_{\mathrm{TOT}}, \mathrm{V}_{30}, \mathrm{~V}_{10}$, and $\mathrm{V}_{3}$, allow direct comparison of values between 157 subjects, at different regions with a given test, and between baseline and follow-up testing. ${ }^{57}$ Octopus perimetry is thereby 158 increasingly the static perimeter of choice, both in clinic and in studies/trials - and is being applied as a primary or secondary 159 endpoint in multiple studies and trials including RPGR (NCT04671433), USH2A (NCT03780257) and RPE65 160 (NCT02781480).

161 Fundus-guided perimetry/microperimetry (MP) consists of a static perimetry device with eye tracking and fixation 162 stabilization features, that allows measurement of the sensitivity threshold of individual macular loci under direct retinal 163 visualization, facilitating correlation between structure (especially OCT) and function, and allowing quantification of fixation 
164 stability and topographical localization of retinal loci. However, the presence of unstable/poor fixation, which is commonplace

165 in IRD, can lead to registration difficulties. Furthermore, despite their popularity, there is no consensus on the type of retinal

166 sensitivity parameters that should be used to monitor progression and responses to therapeutic intervention. ${ }^{64}$ For these

167 reasons, it is arguably less reliable than SP; also, it only tests macular function. MP devices with a broad range of testing

168 abilities (mesopic, photopic and dual-colour scotopic testing) and dynamic ranges are available, including the most

169 commonly used Macular Integrity Assessment (MAIA; CenterVue, Padova, Italy) and Nidek microperimeters (Nidek

170 Technologies Srl, Padova, Italy). MP has been used to characterize and monitor the progression of multiple IRDs, including

171 - STGD, ${ }^{61,65}$ ACHM, ${ }^{22}$ and both syndromic and non-syndromic USH2A-retinopathy; ${ }^{53}$ as well as in clinical trials of gene

172 therapy for RPE65-LCA (NCT00643747)66 and RPGR-RCD (NCT03252847), pharmacological trials for STGD

173 (NCT03735810, NCT03033108, NCT02402660, NCT03364153), and transplantation of human embryonic stem cell-derived

174 (hESC-) retinal pigment epithelial (RPE) cells in STGD (NCT01469832). ${ }^{67}$

175

\section{Dark Adaptometry}

177 Measuring dark adaptation (DA) provides insight into photoreceptor thresholds and kinetics. Canonical and rapid 178 adaptometers exist, with Goldmann-Weekers being the most commonly employed. ${ }^{68}$ DA curves show how retinal sensitivity 179 changes at set locations, after switching from photopic to scotopic conditions. ${ }^{69}$ DA is typically biphasic, with an initially 180 cone-mediated phase, followed by a cone-rod breakpoint, and a final, longer phase representing rod function. ${ }^{70}$ Elevated 181 thresholds of DA have been reported in a broad range of conditions, including $\mathrm{RCD},{ }^{71-73} \mathrm{CORD},{ }^{74} \mathrm{ACHM},{ }^{69} \mathrm{congenital}$ 182 stationary night blindness, ${ }^{75}$ and STGD. ${ }^{76}$

183 Newer devices have been developed; portable, LED-based dark adaptometers such as the Scotopic Sensitivity 184 Tester (SST-1) from LKC Technologies Inc. (Gaithersburg, MD, USA), ${ }^{77}$ and instruments with increased testing efficiency. 
Among the latter, the AdaptDx (MacuLogix, Hummelstown, PA) has been used to study delayed DA mainly in age related macular degeneration (AMD). ${ }^{78}$ Higgins et al. have recently proposed a novel 'time-to-event' analysis method that can be applied to this data, providing better statistical power. ${ }^{79}$

\section{Assessment of Photoaversion}

Testing of light discomfort threshold has been implemented in several conditions such as migraine, blepharospasm, LCA and $\mathrm{ACHM} .{ }^{80-84}$ The technique used for the first three entities was similar: increasing luminance stimuli were presented to the subject until he/she pressed a button, indicating that the stimulus was uncomfortable and ending the test. ${ }^{80}$ For ACHM, an arguably more objective and precise approach has been proposed. ${ }^{85}$ This involves video-recording the subject's reaction to different light exposures and capturing various metrics such as average distance between the eyelids (palpebral fissure aperture) ${ }^{81,83}$ This method has been included to monitor efficacy in two on-going ACHM gene therapy trials: CNGB3NCT03001310 and CNGA3- NCT03758404. Other gene therapy trials, such as CNGA3- NCT02935517 and CNGB3NCT02599922, have implemented a device called the Ocular Photosensitivity Analyser (OPA) as a secondary outcome measure. The OPA uses a concave LED and measures patient indication of pain threshold, along with several further metrics such as inter-blink interval and pupil diameter. ${ }^{85,86}$

Identifying the most sensitive way to measure and compare photoaversion is certainly challenging. Different groups have proposed their own method, with different approaches regarding adaptation to light levels (Verriotto et al. adapt at 100 lux, while Aboshiha et al. use total darkness), ${ }^{84,85}$ stimuli intensity and colour, and outcome metrics. A consensus is yet to be established. Qualitative assessments of photoaversion are also being explored and will no doubt be complimentary to the aforementioned objective assessments; these include the questionnaire developed for the CNGA3- NCT02610582 trial, 'A3-PRO', 87,88 and the Visual Light Sensitivity Questionnaire-8, designed by Verriotto et al. ${ }^{85}$ 
208 The electroretinogram (ERG) can be a valuable tool in the diagnosis and characterisation of IRD, especially those with 209 pathognomonic ERG features such as IRD associated with NR2E3 and KCNV2, ${ }^{89}$ being able to probe the extent, degree 210 and cellular nature of dysfunction objectively..$^{90}$ Electrophysiological assessment is also helpful in providing better informed 211 advice on prognosis (particularly in STGD), ${ }^{91}$ in the differential diagnosis of childhood nystagmus/poor vision from birth/early 212 infancy, ${ }^{92}$ and helping to distinguish between late-onset IRD and autoimmune retinopathy. ${ }^{93,94}$ However, the test-retest 213 variability of ERG is high (20-30\%), making it insensitive to measuring change overtime clinically or in clinical trials; with 214 patients also often reporting reluctance to have serial electrophysiological testing. ${ }^{95-97}$

Full-field (ff) ERG measures the global retinal electrical potential changes provoked by light stimuli, under light- and dark-adapted conditions, to provide information on generalized retinal function of both rod and cone systems. ${ }^{98}$ The 217 International Society for Clinical Electrophysiology of Vision (ISCEV) recommends a minimum of six stimuli for a complete 218 clinical ERG assessment. ${ }^{90}$ Two of the most important components of the ERG are the $a$ and $b$ waveforms. The a wave 219 corresponds to the initial negative deflection and originates from the light-induced hyperpolarization of rod and cone outer 220 segments. $^{98}$ The $\mathrm{b}$ wave is the positive deflection following the a wave, and represents bipolar cell depolarization. 221 Photoreceptor disorders (e.g. RCD, CORD, ACHM) affect both the a and b wave, whereas conditions involving the post222 photoreceptor signal transduction (e.g. X-linked retinoschisis) selectively reduce the b wave, causing an 'electronegative 223 waveform' (b/a ratio <1.0). ${ }^{99}$ Macular function can be explored with a range of electrophysiological assessments, including 224 multifocal (mf) ERG, focal ERG, and pattern ERG (PERG). Such testing may be helpful in the diagnosis of e.g. RP1L1225 occult macular dystrophy, ${ }^{100}$ and structure-function correlations including between PERG/mfERG and the high intensity 226 autofluorescence perimacular ring often seen in RCD and CORD. ${ }^{12}$ 
adapted amplitude to the minimum dark-adapted amplitude (Arden ratio, $\geq 1.8$ in normal eyes). The EOG ratio is often reduced when the ffERG is abnormal, and is generally abnormal in autosomal dominant Best disease, where a decreased Arden ratio with normal ffERG is characteristic. ${ }^{102}$

Visual Evoked Potentials (VEP) are used to evaluate the integrity of the complete visual pathway, and depend highly on central visual function. ISCEV recommends three basic stimuli: flash (useful for media opacity), pattern reversal (for both pre- and post-chiasmal lesions), and pattern on/off (provides estimates of potential VA). ${ }^{103}$

Lastly, full-field light sensitivity threshold (FST) testing is a dark-adapted assessment with white, blue, green and red full-field stimuli, providing a psychophysical assessment of luminance thresholds; which unlike the aformentioned electrophysiological assessments lacks international standardisation. ${ }^{104}$ By comparing the responses to stimuli of different wavelengths, inference can be made about which mechanisms are primarily mediating the response. ${ }^{104}$ FST has been correlated with dark-adapted perimetry derived retinal sensitivity in a cohort of subjects with a range of IRD. ${ }^{105}$ FST has also been correlated with OCT parameters and BCVA in patients with STGD, ${ }^{106}$ with disease duration in individuals with USH2Aassociated retinopathy (both syndromic and isolated), ${ }^{107}$ and with ffERG amplitude in patients with RCD. ${ }^{108}$ FST has a testretest variability of around $0.3 \mathrm{log} \mathrm{cd} / \mathrm{m}^{2}$ and has been used as a secondary outcome measure in gene therapy clinical trials for IRD, including the pivotal trial leading to approved treatment for RPE65-associated retinal dystrophy. ${ }^{109,110}$

\section{Patient-Reported Outcome Measures}

Comprehensively understanding the patient experience while living with an IRD is key to fully measuring the impact of IRD including emotionally, psychologically, socially and financially, and is critical to the provision of appropriate management and the development and approval of treatments. Several standardised questionnaires have shown significant reliability and validity and are included in research settings as patient-reported outcome measures (PROs). ${ }^{111-113}$ 

to evaluate vision-related quality of life in visually impaired individuals. A version consisting of 25 items (VFQ25) has been

252 validated and used in the CHM gene therapy clinical trial (NCT01461213) and pivotal RPE65-RCD trial, among others. ${ }^{114-}$

253116 The Impact of Vision Impairment (IVI) questionnaire is another option and is available in adult (IVI-A) and child-friendly 254 (IVI-C) versions, and is being used as a secondary outcome measure in RPGR-RCD and ACHM gene therapy trials 255 (NCT04671433, NCT03001310 and NCT03758404). ${ }^{117}$ Particularly for RCD, Szlyk et al. have developed questionnaires 256 that showed strong correlation with BCVA, CS and VF. ${ }^{118,119}$ The Vision Function Scale-plus (19 items) survey, initially

257 developed for cataract, has also provided promising results in RCD. ${ }^{120}$ Recently, the Michigan Retinal Degeneration 258 Questionnaire was also validated as a PRO for patients with IRD, employing 59 items in 7 domains. ${ }^{121}$

Whilst there remains no consensus on the most appropriate PRO tools in IRD and whether they need to be disease/genotype specific given the extreme clinical heterogeneity of IRD, they provide clinically meaningful information for both patients and researchers and are an integral assessment to fully evaluate treatment efficacy and calculate cost-

262 effectiveness.

\section{Functional Magnetic Resonance Imaging (fMRI)}

$265 \mathrm{MRI}$ can provide anatomical, physiological and functional information in a single, non-interventional setting. Functional MRI 266 commonly uses the blood oxygenation level-dependent (BOLD) technique, which shows increased signal as 267 deoxyhemoglobin concentration decreases, and vice versa. ${ }^{122} \mathrm{fMRI}$ has allowed the delineation of retinotopic and 268 population-receptive field maps, which connect visually stimulated retinal regions with a corresponding visual cortex area 269 that responds to this stimulation with an increased BOLD signal. ${ }^{123}$ BOLD fMRI has been used to assess how the visual 270 cortex responded to retinal gene therapy in patients with RPE65-LCA, ${ }^{124}$ and has also recently identified new cone-driven 
signals in visual cortical areas in a child with ACHM, following gene therapy (NCT03758404 and NCT03001310), with plans

272 for fMRI to be incorporated into other ACHM gene therapy trials. ${ }^{125}$

\section{Vision-guided mobility}

275 Orientation and Mobility testing (MT) is a way of assessing functional vision, and can be defined as the physical ability to

276 move efficiently and safely in an environment. Assessments of vision-guided mobility can be helpful in exploring the impact

277 of vision on everyday function, with impaired mobility having been associated with reduced wellbeing. Constricted VF, as

278 well as nyctalopia, seen in RCD and other IRD, are known to markedly impair mobility. ${ }^{126-128}$

Increasingly IRD trials, including the pivotal trial for RPE65-LCA (where mobility was the primary outcome), employ assessments to quantify vision-guided mobility before and after intervention; with multiple mobility assessments developed to date, including with or without obstacles, with or without visual acuity dependent prompts, performed under a range of different lighting conditions, and of varying sizes and complexities. ${ }^{110,129,130}$ One of the most important MT assessments was the one custom designed for the RPE65 gene therapy pivotal trial (NCT00999609), which was named multi-luminance mobility testing (MLMT) and had a dimension of $7 \times 12 \mathrm{ft}$ (equivalent to $2.1 \times 3.6 \mathrm{~m}$ ); ${ }^{131}$ for which patients were dark adapted and asked to navigate a path, making turns and avoiding obstacles, with one and/or both eyes open. Other groups have employed a mixed indoors and outdoors setting, ${ }^{132}$ while others have directly utilized true real-life scenarios such as shopping malls ${ }^{128}$ and sections of hospitals. ${ }^{133}$ RPE65- NCT02781480 and RPGR- NCT03252847 have chosen a different

288 type of MT, with a dimension of $7.2 \times 10.8 \mathrm{~m}$, and an adjustable modular platform at decreasing, standardised lighting levels (Figure 2). This test can also include obstacles and has been validated for use in subjects with RPE65-LCA. ${ }^{134}$

The metrics used to quantify performance on these mobility assessments have varied, however the most commonly employed are the time taken to navigate the course and/or the errors made during navigation, at a given illumination level.

292 These have been used as either continuous variables or incorporated into a pass/fail criterion; and have been included as 
both inclusion criteria and primary outcome measures in several clinical trials and validation studies. ${ }^{129,131,134,135}$ An

294 association between MT parameters and VF has been most strongly established, ${ }^{134,136}$ with a correlation with BCVA ${ }^{135}$ and

295 CS also reported. ${ }^{132}$ Of note, central field loss has not appeared to be as limiting for mobility as peripheral loss. ${ }^{51}$ It remains

296 likely that these correlations will be partly disease dependent and/or severity related.

The capability to navigate independently in dim environments contributes to quality of life and productivity. ${ }^{137}$

299 understanding how patients perform on a daily basis and how treatments can help improve their quality of life and increase

300 their independence.

301

\section{Virtual Reality and New Methodologies}

304 VR technology has become readily available, providing flexibility, reproducibility, participant engagement, safety, and the 305 ability to tailor countless scenarios with excellent ecological validity (highly accurate designs, displaying the relevant features 306 of the environment). ${ }^{139}$ A recent study has tested a VR MT in patients with RPE65-LCA, providing proof-of-concept of the 307 utility of this approach and encouraging further broader application to IRD, and potentially resulting in mobility assessments 308 being more accessible and varied. ${ }^{140}$

309 Another interesting field has been the development of tools and applications (apps) that can assess aspects of vision 310 while we use our own digital devices. ${ }^{141}$ Information about VF, tracking, CV, CS and VA can be estimated through the use 311 of apps, again potentially providing a more accessible (and arguably more directly functionally relevant) way of 312 characterizing and monitoring vision ${ }^{141,142}$ Standardization and validation of such approaches will be necessary. 


\section{Conclusions}

316 Functional testing in IRD has gained increasing relevance over the last decade, superseding structural assessments in

317 providing evidence of efficacy in clinical trials of treatments, ${ }^{143}$ given that improvement in function is generally being

318 recorded, thereby shifting the emphasis away from slowing/halting retinal degeneration which is often focused on

319 structure. ${ }^{115,131}$ Although some of the assessments provide unique, novel information such as real-life mobility performance,

320 most clinically meaningful features can be assessed through a range of modalities e.g. macular function can be evaluated

321 through static perimetry, microperimetry, CV, BCVA, CS, etc. Ideally, following a genetic diagnosis, patients with IRD should

322 have both a structural and functional multimodal evaluation, to fully characterize their disorder, help to provide better

323 informed advice on prognosis, as well as facilitate determination of eligibility and end-points for interventional clinical trials. 


\section{Legends}

326 Figure 1: Example of semi-automated static Octopus perimetry and corresponding Visual Field Modelling and Analysis

327 (VFMA), displaying the total hill-of-vision volumetric output ( $\vee_{\text {TOT }}$ ). A) Baseline assessment of an individual with RPGR-

$328 \mathrm{RCD}$, with a $\mathrm{V}_{\text {TOT }}$ of 35.68 decibel-steradians (dB-sr). The latter combines the magnitude and extent of the sensitivity

329 across the test grid. B) Four-year follow up of the same patient, demonstrating a decreased $V_{\text {TOT }}$ of $17.28 \mathrm{~dB}$-sr. C)

330 Subtraction analysis of VFMA at baseline (A) and follow-up (B), allowing direct comparison. The 3D image enables us to

331 visualize the representation from above, below, and different angles, to also qualitatively assess the areas where

332 sensitivity has changed, while quantitative analysis reveals a $\Delta \mathrm{V}_{\text {ТОт }}$ of $-17.07 \mathrm{~dB}$-sr between both time-points.

333

334 Figure 2: Example of mobility assessment. "Fisheye" view from overhead camera showing the Visual Mobility Assessment

335 configuration used in NCT02781480 and NCT02714816 to evaluate individuals affected by RPE65-associated retinal

336 dystrophy. 
338 Contributors: All authors contributed to the design of this review article, literature review, manuscript preparation and review.

339 The authors were responsible for all content and editorial decision.

340

341 Declaration of interest: The authors alone are responsible for the content and writing of this article. MM consults for 342 MeiraGTx, Stargazer Pharmaceuticals, Janssen Pharmaceuticals, 2C Tech, Acucela and Roche.

343

344 Funding: This work has been supported by grants from The Wellcome Trust [099173/Z/12/Z], the National Institute for Health

345 Research Biomedical Research Centre at Moorfields Eye Hospital NHS Foundation Trust and UCL Institute of

346 Ophthalmology, Moorfields Eye Charity, and Retina UK. The views expressed are those of the authors and not necessarily

347 those of the NHS, the NIHR or the Department of Health. 


\section{References}

1. Georgiou M, Fujinami K, Michaelides M. Inherited retinal diseases: Therapeutics, clinical trials and end-points - A review. Clin Experiment Ophthalmol. Published online March 2021. doi:10.1111/ceo.13917

2. Kumaran N, Georgiou M, Bainbridge JWB, et al. Retinal Structure in RPE65-Associated Retinal Dystrophy. Invest Ophthalmol Vis Sci. 2020;61(4):47. doi:10.1167/iovs.61.4.47

3. Gill JS, Georgiou M, Kalitzeos A, Moore AT, Michaelides M. Progressive cone and cone-rod dystrophies: clinical features, molecular genetics and prospects for therapy. Br J Ophthalmol. 2019;103(5):711-720. doi:10.1136/bjophthalmol-2018-313278

4. Aboshiha J, Dubis AM, Carroll J, Hardcastle AJ, Michaelides M. The cone dysfunction syndromes. Br J Ophthalmol. 2016;100(1):115-121. doi:10.1136/bjophthalmol-2014-306505

5. Kaiser PK. Prospective evaluation of visual acuity assessment: a comparison of snellen versus ETDRS charts in clinical practice (An AOS Thesis). Trans Am Ophthalmol Soc. 2009;107:311-324.

6. Bailey IL, Lovie JE. New design principles for visual acuity letter charts. Am J Optom Physiol Opt. 1976;53(11):740745. doi:10.1097/00006324-197611000-00006

7. Ferris FL 3rd, Kassoff A, Bresnick GH, Bailey I. New visual acuity charts for clinical research. Am J Ophthalmol. 1982;94(1):91-96.

8. Raasch TW, Bailey IL, Bullimore MA. Repeatability of visual acuity measurement. Optom Vis Sci Off Publ Am Acad Optom. 1998;75(5):342-348. doi:10.1097/00006324-199805000-00024

9. Chaplin PKN, Bradford GE. A historical review of distance vision screening eye charts: what to toss, what to keep, and what to replace. NASN Sch Nurse. 2011;26(4):221-228. doi:10.1177/1942602x11411094

10. Hirji N, Aboshiha J, Georgiou M, Bainbridge J, Michaelides M. Achromatopsia: clinical features, molecular genetics, animal models and therapeutic options. Ophthalmic Genet. 2018;39(2):149-157. 
doi:10.1080/13816810.2017.1418389

11. Kumaran N, Moore AT, Weleber RG, Michaelides M. Leber congenital amaurosis/early-onset severe retinal dystrophy: clinical features, molecular genetics and therapeutic interventions. Br J Ophthalmol. 2017;101(9):11471154. doi:10.1136/bjophthalmol-2016-309975

12. Robson AG, Michaelides M, Saihan Z, et al. Functional characteristics of patients with retinal dystrophy that manifest abnormal parafoveal annuli of high density fundus autofluorescence; a review and update. Doc Ophthalmol. 2008;116(2):79-89. doi:10.1007/s10633-007-9087-4

13. Hara A, Nakazawa M, Saito M, Suzuki Y. The qualitative assessment of optical coherence tomography and the central retinal sensitivity in patients with retinitis pigmentosa. PLoS One. 2020;15(5):e0232700. doi:10.1371/journal.pone.0232700

14. Abe K, lijima H, Hirakawa H, Tsukahara $\mathrm{Y}$, Toda $\mathrm{Y}$. Visual acuity and 10 degrees automated static perimetry in eyes with retinitis pigmentosa. Jpn J Ophthalmol. 2002;46(5):581-585. doi:10.1016/s0021-5155(02)00548-8

15. lijima $\mathrm{H}$. Visual loss and perimetric sensitivity in eyes with retinitis pigmentosa. Jpn J Ophthalmol. 2013;57(6):563567. doi:10.1007/s10384-013-0271-7

16. Ratnam K, Carroll J, Porco TC, Duncan JL, Roorda A. Relationship between foveal cone structure and clinical measures of visual function in patients with inherited retinal degenerations. Invest Ophthalmol Vis Sci. 2013;54(8):5836-5847. doi:10.1167/iovs.13-12557

17. Sunness JS, Rubin GS, Broman A, Applegate CA, Bressler NM, Hawkins BS. Low luminance visual dysfunction as a predictor of subsequent visual acuity loss from geographic atrophy in age-related macular degeneration. Ophthalmology. 2008;115(9):1480-1488, 1488.e1-2. doi:10.1016/j.ophtha.2008.03.009

18. Bittner AK, Ferraz MC. Reliability of Mesopic Measures of Visual Acuity and Contrast Sensitivity and Their Correlation with Rod and Cone Function in Retinitis Pigmentosa. Ophthalmic Res. 2020;63(2):133-140. 
doi:10.1159/000503931

19. Alexander KR, Derlacki DJ, Fishman GA, Peachey NS. Acuity-luminance and foveal increment threshold functions in retinitis pigmentosa. Invest Ophthalmol Vis Sci. 1991;32(5):1446-1454.

20. Lindberg CR, Fishman GA, Anderson RJ, Vasquez V. Contrast sensitivity in retinitis pigmentosa. Br J Ophthalmol. 1981;65(12):855-858. doi:10.1136/bjo.65.12.855

21. Alahmadi BO, Omari AA, Abalem MF, et al. Contrast sensitivity deficits in patients with mutation-proven inherited retinal degenerations. BMC Ophthalmol. 2018;18(1):313. doi:10.1186/s12886-018-0982-0

22. Georgiou M, Singh N, Kane T, et al. Long-Term Investigation of Retinal Function in Patients with Achromatopsia. Invest Ophthalmol Vis Sci. 2020;61(11):38. doi:10.1167/iovs.61.11.38

23. Hou F, Lesmes LA, Kim W, et al. Evaluating the performance of the quick CSF method in detecting contrast sensitivity function changes. J Vis. 2016;16(6):18. doi:10.1167/16.6.18

24. Huchzermeyer C, Fars J, Kremers J. Photoreceptor-Specific Loss of Perifoveal Temporal Contrast Sensitivity in Retinitis Pigmentosa. Trans/ Vis Sci Technol. 2020;9(6):27. doi:10.1167/tvst.9.6.27

25. Huchzermeyer C, Fars J, Stöhr H, Kremers J. [New techniques for quantification of color vision in disorders of cone function : Cambridge color test and photoreceptor-specific temporal contrast sensitivity in patients with heterozygous RP1L1 and RPGR mutations]. Ophthalmologe. 2021;118(2):144-153. doi:10.1007/s00347-02001119-0

26. Burton E, Wattam-Bell J, S Rubin G, et al. Dissociations in Coherence Sensitivity Reveal Atypical Development of Cortical Visual Processing in Congenital Achromatopsia. Invest Ophthalmol Vis Sci. 2016;57(4):2251-2259. doi:10.1167/iovs.15-18414

27. Virgili G, Pierrottet C, Parmeggiani F, et al. Reading performance in patients with retinitis pigmentosa: a study using the MNREAD charts. Invest Ophthalmol Vis Sci. 2004;45(10):3418-3424. doi:10.1167/iovs.04-0390 
28. Murro V, Sodi A, Giacomelli G, et al. Reading Ability and Quality of Life in Stargardt Disease. Eur J Ophthalmol. 2017;27(6):740-745. doi:10.5301/ejo.5000972

29. Alexander KR, Derlacki DJ, Fishman GA. Visual acuity vs letter contrast sensitivity in retinitis pigmentosa. Vision Res. 1995;35(10):1495-1499. doi:10.1016/0042-6989(95)98729-s

30. Akeo K, Hiida Y, Saga M, Inoue R, Oguchi Y. Correlation between contrast sensitivity and visual acuity in retinitis pigmentosa patients. Ophthalmol J Int d'ophtalmologie Int J Ophthalmol Zeitschrift fur Augenheilkd. 2002;216(3):185-191. doi:10.1159/000059627

31. Oishi M, Nakamura H, Hangai M, Oishi A, Otani A, Yoshimura N. Contrast visual acuity in patients with retinitis pigmentosa assessed by a contrast sensitivity tester. Indian J Ophthalmol. 2012;60(6):545-549. doi:10.4103/03014738.103793

32. Talib M, van Schooneveld MJ, van Duuren RJG, et al. Long-Term Follow-Up of Retinal Degenerations Associated With LRAT Mutations and Their Comparability to Phenotypes Associated With RPE65 Mutations. Trans/ Vis Sci Technol. 2019;8(4):24. doi:10.1167/tvst.8.4.24

33. Jolly JK, Groppe M, Birks J, Downes SM, MacLaren RE. Functional Defects in Color Vision in Patients With Choroideremia. Am J Ophthalmol. 2015;160(4):822-31.e3. doi:10.1016/j.ajo.2015.06.018

34. Fanlo Zarazaga A, Gutiérrez Vásquez J, Pueyo Royo V. Review of the main colour vision clinical assessment tests. Arch Soc Esp Oftalmol. 2019;94(1):25-32. doi:10.1016/j.oftal.2018.08.006

35. Cole BL, Lian K-Y, Lakkis C. The new Richmond HRR pseudoisochromatic test for colour vision is better than the Ishihara test. Clin Exp Optom. 2006;89(2):73-80. doi:10.1111/j.1444-0938.2006.00015.x

36. Dain SJ. Clinical colour vision tests. Clin Exp Optom. 2004;87(4-5):276-293. doi:10.1111/j.14440938.2004.tb05057.x

37. Kumaran N, Ripamonti C, Kalitzeos A, Rubin GS, Bainbridge JWB, Michaelides M. Severe Loss of Tritan Color 
Discrimination in RPE65 Associated Leber Congenital Amaurosis. Invest Ophthalmol Vis Sci. 2018;59(1):85-93. doi:10.1167/iovs.17-22905

38. Ripamonti C, Kalwarowsky S, Nardini M. A Universal Colour Discrimination Test suitable for observers with low vision. Invest Ophthalmol Vis Sci. 2014;55(13):3536.

39. Berson EL, Sandberg MA, Rosner B, Sullivan PL. Color plates to help identify patients with blue cone monochromatism. Am J Ophthalmol. 1983;95(6):741-747. doi:10.1016/0002-9394(83)90058-2

40. McClements M, Davies WIL, Michaelides M, et al. X-linked cone dystrophy and colour vision deficiency arising from a missense mutation in a hybrid L/M cone opsin gene. Vision Res. 2013;80:41-50. doi:10.1016/j.visres.2012.12.012

41. Patterson EJ, Wilk M, Langlo CS, et al. Cone Photoreceptor Structure in Patients With X-Linked Cone Dysfunction and Red-Green Color Vision Deficiency. Invest Ophthalmol Vis Sci. 2016;57(8):3853-3863. doi:10.1167/iovs.1619608

42. Traquair HM. An introduction to clinical perimetry, 1st edn, Vol. VIII London Henry Kimpt. $1927 ; 254$.

43. Grover S, Fishman GA, Brown JJ. Patterns of visual field progression in patients with retinitis pigmentosa. Ophthalmology. 1998;105(6):1069-1075. doi:10.1016/S0161-6420(98)96009-2

44. Fishman GA, Bozbeyoglu S, Massof RW, Kimberling W. Natural course of visual field loss in patients with Type 2 Usher syndrome. Retina. 2007;27(5):601-608. doi:10.1097/01.iae.0000246675.88911.2c

45. Bittner AK, Iftikhar MH, Dagnelie G. Test-retest, within-visit variability of Goldmann visual fields in retinitis pigmentosa. Invest Ophthalmol Vis Sci. 2011;52(11):8042-8046. doi:10.1167/iovs.11-8321

46. Birch DG, Locke KG, Felius J, et al. Rates of decline in regions of the visual field defined by frequency-domain optical coherence tomography in patients with RPGR-mediated X-linked retinitis pigmentosa. Ophthalmology. 2015;122(4):833-839. doi:10.1016/j.ophtha.2014.11.005

47. Birch DG, Weleber RG, Duncan JL, Jaffe GJ, Tao W. Randomized trial of ciliary neurotrophic factor delivered by 
encapsulated cell intraocular implants for retinitis pigmentosa. Am J Ophthalmol. 2013;156(2):283-292.e1. doi:10.1016/j.ajo.2013.03.021

48. Berson EL, Rosner B, Sandberg MA, et al. Clinical trial of lutein in patients with retinitis pigmentosa receiving vitamin A. Arch Ophthalmol (Chicago, III 1960). 2010;128(4):403-411. doi:10.1001/archophthalmol.2010.32

49. Racette L, Fischer M, Bebie H, Holló G, Johnson CA, Matsumoto C. Visual field digest: A guide to perimetry and the Octopus perimeter. Köniz, Switz Haag-Streit AG. 2016;289.

50. Strauss RW, Ho A, Muñoz B, et al. The Natural History of the Progression of Atrophy Secondary to Stargardt Disease (ProgStar) Studies: Design and Baseline Characteristics: ProgStar Report No. 1. Ophthalmology. 2016;123(4):817-828. doi:10.1016/j.ophtha.2015.12.009

51. Kumaran N, Rubin GS, Kalitzeos A, et al. A Cross-Sectional and Longitudinal Study of Retinal Sensitivity in RPE65Associated Leber Congenital Amaurosis. Invest Ophthalmol Vis Sci. 2018;59(8):3330-3339. doi:10.1167/iovs.1823873

52. Tee JJL, Yang Y, Kalitzeos A, et al. Characterization of Visual Function, Interocular Variability and Progression Using Static Perimetry-Derived Metrics in RPGR-Associated Retinopathy. Invest Ophthalmol Vis Sci. 2018;59(6):2422-2436. doi:10.1167/iovs.17-23739

53. Duncan JL, Liang W, Maguire MG, et al. Baseline Visual Field Findings in the RUSH2A Study: Associated Factors and Correlation With Other Measures of Disease Severity. Am J Ophthalmol. 2020;219:87-100. doi:10.1016/j.ajo.2020.05.024

54. Kutzko KE, Brito CF, Wall M. Effect of instructions on conventional automated perimetry. Invest Ophthalmol Vis Sci. 2000;41(7):2006-2013.

55. Hoffman DR, Hughbanks-Wheaton DK, Spencer R, et al. Docosahexaenoic Acid Slows Visual Field Progression in X-Linked Retinitis Pigmentosa: Ancillary Outcomes of the DHAX Trial. Invest Ophthalmol Vis Sci. 
2015;56(11):6646-6653. doi:10.1167/iovs.15-17786

56. Murata H, Asaoka R, Fujino $\mathrm{Y}$, et al. Comparing the usefulness of a new algorithm to measure visual field using the variational Bayes linear regression in glaucoma patients, in comparison to the Swedish interactive thresholding algorithm. Br J Ophthalmol. Published online January 2021. doi:10.1136/bjophthalmol-2020-318304

57. Schiefer U, Pascual JP, Edmunds B, et al. Comparison of the new perimetric GATE strategy with conventional fullthreshold and SITA standard strategies. Invest Ophthalmol Vis Sci. 2009;50(1):488-494. doi:10.1167/iovs.08-2229

58. Birch DG, Bennett LD, Duncan JL, Weleber RG, Pennesi ME. Long-term Follow-up of Patients With Retinitis Pigmentosa Receiving Intraocular Ciliary Neurotrophic Factor Implants. Am J Ophthalmol. 2016;170:10-14. doi:10.1016/j.ajo.2016.07.013

59. Nakazawa M, Ohguro H, Takeuchi K, Miyagawa Y, Ito T, Metoki T. Effect of nilvadipine on central visual field in retinitis pigmentosa: a 30-month clinical trial. Ophthalmol J Int d'ophtalmologie Int J Ophthalmol Zeitschrift fur Augenheilkd. 2011;225(2):120-126. doi:10.1159/000320500

60. Weleber RG, Smith TB, Peters D, et al. VFMA: Topographic Analysis of Sensitivity Data From Full-Field Static Perimetry. Trans/ Vis Sci Technol. 2015;4(2):14. doi:10.1167/tvst.4.2.14

61. Tanna P, Georgiou M, Aboshiha J, et al. Cross-Sectional and Longitudinal Assessment of Retinal Sensitivity in Patients With Childhood-Onset Stargardt Disease. Trans/ Vis Sci Technol. 2018;7(6):10. doi:10.1167/tvst.7.6.10

62. Josan AS, Buckley TMW, Wood LJ, Jolly JK, Cehajic-Kapetanovic J, MacLaren RE. Microperimetry Hill of Vision and Volumetric Measures of Retinal Sensitivity. Trans/ Vis Sci Technol. 2021;10(7):12. doi:10.1167/tvst.10.7.12

63. Subash M, Comyn O, Samy A, et al. The Effect of Multispot Laser Panretinal Photocoagulation on Retinal Sensitivity and Driving Eligibility in Patients With Diabetic Retinopathy. JAMA Ophthalmol. 2016;134(6):666-672. doi:10.1001/jamaophthalmol.2016.0629

64. Wong EN, Mackey DA, Morgan WH, Chen FK. Intersession test-retest variability of conventional and novel 
parameters using the MP-1 microperimeter. Clin Ophthalmol. 2016;10:29-42. doi:10.2147/OPTH.S92018

65. Schönbach EM, Janeschitz-Kriegl L, Strauss RW, et al. The Progression of Stargardt Disease using Volumetric Hill of Vision Analyses Over 24 Months: ProgStar Report No.15. Am J Ophthalmol. Published online May 2021. doi:10.1016/j.ajo.2021.04.015

66. Bainbridge JWB, Smith AJ, Barker SS, et al. Effect of gene therapy on visual function in Leber's congenital amaurosis. N Engl J Med. 2008;358(21):2231-2239. doi:10.1056/NEJMoa0802268

67. Mehat MS, Sundaram V, Ripamonti C, et al. Transplantation of Human Embryonic Stem Cell-Derived Retinal Pigment Epithelial Cells in Macular Degeneration. Ophthalmology. 2018;125(11):1765-1775. doi:10.1016/j.ophtha.2018.04.037

68. Yang G-Q, Chen T, Tao Y, Zhang Z-M. Recent advances in the dark adaptation investigations. Int J Ophthalmol. 2015;8(6):1245-1252. doi:10.3980/j.issn.2222-3959.2015.06.31

69. Aboshiha J, Luong V, Cowing J, et al. Dark-adaptation functions in molecularly confirmed achromatopsia and the implications for assessment in retinal therapy trials. Invest Ophthalmol Vis Sci. 2014;55(10):6340-6349. doi:10.1167/iovs.14-14910

70. RUSHTON WA. Dark-adaptation and the regeneration of rhodopsin. J Physiol. 1961;156(1):166-178. doi:10.1113/jphysiol.1961.sp006666

71. Burstedt MS, Forsman-Semb K, Golovleva I, Janunger T, Wachtmeister L, Sandgren O. Ocular phenotype of bothnia dystrophy, an autosomal recessive retinitis pigmentosa associated with an R234W mutation in the RLBP1 gene. Arch Ophthalmol (Chicago, III 1960). 2001;119(2):260-267.

72. Alexander KR, Fishman GA. Prolonged rod dark adaptation in retinitis pigmentosa. Br J Ophthalmol. 1984;68(8):561-569. doi:10.1136/bjo.68.8.561

73. Moore AT, Fitzke FW, Kemp CM, et al. Abnormal dark adaptation kinetics in autosomal dominant sector retinitis 
pigmentosa due to rod opsin mutation. Br J Ophthalmol. 1992;76(8):465-469. doi:10.1136/bjo.76.8.465

74. Michaelides M, Holder GE, Hunt DM, Fitzke FW, Bird AC, Moore AT. A detailed study of the phenotype of an autosomal dominant cone-rod dystrophy (CORD7) associated with mutation in the gene for RIM1. Br J Ophthalmol. 2005;89(2):198-206. doi:10.1136/bjo.2004.050773

75. Kabanarou SA, Holder GE, Fitzke FW, Bird AC, Webster AR. Congenital stationary night blindness and a "Schubert-Bornschein" type electrophysiology in a family with dominant inheritance. Br J Ophthalmol. 2004;88(8):1018-1022. doi:10.1136/bjo.2003.033555

76. Fishman GA, Farbman JS, Alexander KR. Delayed rod dark adaptation in patients with Stargardt's disease. Ophthalmology. 1991;98(6):957-962. doi:10.1016/s0161-6420(91)32196-1

77. Peters AY, Locke KG, Birch DG. Comparison of the Goldmann-Weekers dark adaptometer and LKC Technologies Scotopic Sensitivity tester-1. Doc Ophthalmol. 2000;101(1):1-9. doi:10.1023/a:1002765024774

78. Jackson GR, Edwards JG. A short-duration dark adaptation protocol for assessment of age-related maculopathy. $J$ Ocul Biol Dis Infor. 2008;1(1):7-11. doi:10.1007/s12177-008-9002-6

79. Higgins BE, Montesano G, Binns AM, Crabb DP. Optimising assessment of dark adaptation data using time to event analysis. Sci Rep. 2021;11(1):8323. doi:10.1038/s41598-021-86193-3

80. Collison FT, Park JC, Fishman GA, McAnany JJ, Stone EM. Full-Field Pupillary Light Responses, Luminance Thresholds, and Light Discomfort Thresholds in CEP290 Leber Congenital Amaurosis Patients. Invest Ophthalmol Vis Sci. 2015;56(12):7130-7136. doi:10.1167/iovs.15-17467

81. Vanagaite J, Pareja JA, Støren O, White LR, Sand T, Stovner LJ. Light-induced discomfort and pain in migraine. Cephalalgia. 1997;17(7):733-741. doi:10.1046/j.1468-2982.1997.1707733.x

82. Adams WH, Digre KB, Patel BCK, Anderson RL, Warner JEA, Katz BJ. The evaluation of light sensitivity in benign essential blepharospasm. Am J Ophthalmol. 2006;142(1):82-87. doi:10.1016/j.ajo.2006.02.020 
83. Zelinger L, Cideciyan A V, Kohl S, et al. Genetics and Disease Expression in the CNGA3 Form of Achromatopsia: Steps on the Path to Gene Therapy. Ophthalmology. 2015;122(5):997-1007. doi:10.1016/j.ophtha.2014.11.025

84. Aboshiha J, Kumaran N, Kalitzeos A, Hogg C, Rubin G, Michaelides M. A Quantitative and Qualitative Exploration of Photoaversion in Achromatopsia. Invest Ophthalmol Vis Sci. 2017;58(9):3537-3546. doi:10.1167/iovs.17-21935

85. Verriotto JD, Gonzalez A, Aguilar MC, et al. New Methods for Quantification of Visual Photosensitivity Threshold and Symptoms. Trans/ Vis Sci Technol. 2017;6(4):18. doi:10.1167/tvst.6.4.18

86. Aguilar MC, Gonzalez A, Rowaan C, et al. Automated instrument designed to determine visual photosensitivity thresholds. Biomed Opt Express. 2018;9(11):5583-5596. doi:10.1364/BOE.9.005583

87. Wilhelm B, Koegel A, Kahle N, et al. How do patients rate their subjective symptoms after CNGA3 gene therapy: first application of the instrument A3-PRO. Invest Ophthalmol Vis Sci. 2017;58(8):4678.

88. Fischer MD, Michalakis S, Wilhelm B, et al. Safety and Vision Outcomes of Subretinal Gene Therapy Targeting Cone Photoreceptors in Achromatopsia: A Nonrandomized Controlled Trial. JAMA Ophthalmol. 2020;138(6):643651. doi:10.1001/jamaophthalmol.2020.1032

89. Vincent A, Robson AG, Holder GE. Pathognomonic (diagnostic) ERGs. A review and update. Retina. 2013;33(1):512. doi:10.1097/IAE.0b013e31827e2306

90. McCulloch DL, Marmor MF, Brigell MG, et al. ISCEV Standard for full-field clinical electroretinography (2015 update). Doc Ophthalmol. 2015;130(1):1-12. doi:10.1007/s10633-014-9473-7

91. Fujinami K, Lois N, Davidson AE, et al. A longitudinal study of stargardt disease: clinical and electrophysiologic assessment, progression, and genotype correlations. Am J Ophthalmol. 2013;155(6):1075-1088.e13. doi:10.1016/j.ajo.2013.01.018

92. Suppiej A, Ceccato C, Maritan V, Cermakova I, Colavito D, Leon A. Exome sequencing and electro-clinical features in pediatric patients with very early-onset retinal dystrophies: A cohort study. Eur J Paediatr Neurol EJPN Off J 
Eur Paediatr Neurol Soc. 2021;31:1-9. doi:10.1016/j.ejpn.2021.01.003

93. Soumplis V, Sergouniotis PI, Robson AG, et al. Phenotypic findings in C1QTNF5 retinopathy (late-onset retinal degeneration). Acta Ophthalmol. 2013;91(3):e191-5. doi:10.1111/aos.12010

94. Canamary AMJ, Takahashi WY, Sallum JMF. Autoimmune retinopathy: A Review. Int J Retin Vitr. 2018;4:1. doi:10.1186/s40942-017-0104-9

95. Marcus M, Cabael L, Marmor MF. Are circadian variations in the electroretinogram evident on routine testing? Doc Ophthalmol. 2004;108(2):165-169. doi:10.1023/b:doop.0000036844.67273.1b

96. Fishman GA, Chappelow A V, Anderson RJ, Rotenstreich Y, Derlacki DJ. Short-term inter-visit variability of erg amplitudes in normal subjects and patients with retinitis pigmentosa. Retina. 2005;25(8):1014-1021. doi:10.1097/00006982-200512000-00010

97. Grover S, Fishman GA, Birch DG, Locke KG, Rosner B. Variability of full-field electroretinogram responses in subjects without diffuse photoreceptor cell disease. Ophthalmology. 2003;110(6):1159-1163. doi:10.1016/S01616420(03)00253-7

98. Stevens T. Electrophysiologic Testing in Disorders of the Retina, Optic Nerve, and Visual Pathway, (Ophthalmology Monographs, No. 2). Arch Ophthalmol. 2001;119(11):1734.

99. Ba-Abbad R, Robson AG, Yap YC, Moore AT, Webster AR, Holder GE. Prph2 mutations as a cause of electronegative ERG. Retina. 2014;34(6):1235-1243. doi:10.1097/IAE.0000000000000052

100. Davidson AE, Sergouniotis PI, Mackay DS, et al. RP1L1 variants are associated with a spectrum of inherited retinal diseases including retinitis pigmentosa and occult macular dystrophy. Hum Mutat. 2013;34(3):506-514. doi:10.1002/humu.22264

101. Ryan SJ, Sadda SR. Ryan's Retinal Imaging and Diagnostics E-Book. Elsevier Health Sciences; 2013.

102. Khan KN, Islam F, Holder GE, et al. NORMAL ELECTROOCULOGRAPHY IN BEST DISEASE AND AUTOSOMAL 
RECESSIVE BESTROPHINOPATHY. Retina. 2018;38(2):379-386. doi:10.1097/IAE.0000000000001523

103. Odom JV, Bach M, Brigell M, et al. ISCEV standard for clinical visual evoked potentials: (2016 update). Doc Ophthalmol. 2016;133(1):1-9. doi:10.1007/s10633-016-9553-y

104. Roman AJ, Cideciyan A V, Aleman TS, Jacobson SG. Full-field stimulus testing (FST) to quantify visual perception in severely blind candidates for treatment trials. Physiol Meas. 2007;28(8):N51-6. doi:10.1088/0967-3334/28/8/N02

105. Roman AJ, Schwartz SB, Aleman TS, et al. Quantifying rod photoreceptor-mediated vision in retinal degenerations: dark-adapted thresholds as outcome measures. Exp Eye Res. 2005;80(2):259-272. doi:10.1016/j.exer.2004.09.008

106. Collison FT, Fishman GA, McAnany JJ, Zernant J, Allikmets R. Psychophysical measurement of rod and cone thresholds in stargardt disease with full-field stimuli. Retina. 2014;34(9):1888-1895. doi:10.1097/IAE.0000000000000144

107. Birch DG, Cheng P, Duncan JL, et al. The RUSH2A Study: Best-Corrected Visual Acuity, Full-Field Electroretinography Amplitudes, and Full-Field Stimulus Thresholds at Baseline. Trans/ Vis Sci Technol. 2020;9(11):9. doi:10.1167/tvst.9.11.9

108. Messias K, Jägle H, Saran R, et al. Psychophysically determined full-field stimulus thresholds (FST) in retinitis pigmentosa: relationships with electroretinography and visual field outcomes. Doc Ophthalmol. 2013;127(2):123129. doi:10.1007/s10633-013-9393-y

109. Klein M, Birch DG. Psychophysical assessment of low visual function in patients with retinal degenerative diseases (RDDs) with the Diagnosys full-field stimulus threshold (D-FST). Doc Ophthalmol. 2009;119(3):217-224. doi:10.1007/s10633-009-9204-7

110. Maguire AM, Russell S, Wellman JA, et al. Efficacy, Safety, and Durability of Voretigene Neparvovec-rzyl in RPE65 Mutation-Associated Inherited Retinal Dystrophy: Results of Phase 1 and 3 Trials. Ophthalmology. 2019;126(9):1273-1285. doi:10.1016/j.ophtha.2019.06.017 
111. Mangione CM, Lee PP, Pitts J, Gutierrez P, Berry S, Hays RD. Psychometric properties of the National Eye Institute Visual Function Questionnaire (NEI-VFQ). NEI-VFQ Field Test Investigators. Arch Ophthalmol (Chicago, III 1960). 1998;116(11):1496-1504. doi:10.1001/archopht.116.11.1496

112. Lacy GD, Abalem MF, Musch DC, Jayasundera KT. Patient-reported outcome measures in inherited retinal degeneration gene therapy trials. Ophthalmic Genet. 2020;41(1):1-6. doi:10.1080/13816810.2020.1731836

113. Clemons TE, Chew EY, Bressler SB, McBee W. National Eye Institute visual function questionnaire in the agerelated eye disease study (AREDS): AREDS report no. 10. Arch Ophthalmol. 2003;121(2):211-217.

114. Mangione CM, Lee PP, Gutierrez PR, Spritzer K, Berry S, Hays RD. Development of the 25-item National Eye Institute Visual Function Questionnaire. Arch Ophthalmol (Chicago, III 1960). 2001;119(7):1050-1058. doi:10.1001/archopht.119.7.1050

115. Bainbridge JWB, Mehat MS, Sundaram V, et al. Long-term effect of gene therapy on Leber's congenital amaurosis. N Engl J Med. 2015;372(20):1887-1897. doi:10.1056/NEJMoa1414221

116. MacLaren RE, Groppe M, Barnard AR, et al. Retinal gene therapy in patients with choroideremia: initial findings from a phase 1/2 clinical trial. Lancet (London, England). 2014;383(9923):1129-1137. doi:10.1016/S01406736(13)62117-0

117. Lamoureux EL, Pallant JF, Pesudovs K, Hassell JB, Keeffe JE. The Impact of Vision Impairment Questionnaire: an evaluation of its measurement properties using Rasch analysis. Invest Ophthalmol Vis Sci. 2006;47(11):4732-4741. doi:10.1167/iovs.06-0220

118. Szlyk JP, Fishman GA, Alexander KR, Revelins BI, Derlacki DJ, Anderson RJ. Relationship between difficulty in performing daily activities and clinical measures of visual function in patients with retinitis pigmentosa. Arch Ophthalmol (Chicago, III 1960). 1997;115(1):53-59. doi:10.1001/archopht.1997.01100150055009

119. Lodha N, Westall CA, Brent M, Abdolell M, Héon E. A modified protocol for the assessment of visual function in 
patients with retinitis pigmentosa. Adv Exp Med Biol. 2003;533:49-57. doi:10.1007/978-1-4615-0067-4_7

120. Costela FM, Pesudovs K, Sandberg MA, Weigel-DiFranco C, Woods RL. Validation of a vision-related activity scale for patients with retinitis pigmentosa. Health Qual Life Outcomes. 2020;18(1):196. doi:10.1186/s12955-020-014278

121. Lacy GD, Abalem MF, Andrews CA, et al. The Michigan Retinal Degeneration Questionnaire: A Patient-Reported Outcome Instrument for Inherited Retinal Degenerations. Am J Ophthalmol. 2021;222:60-68. doi:10.1016/j.ajo.2020.08.032

122. Duong TQ, Muir ER. Magnetic resonance imaging of the retina. Jpn J Ophthalmol. 2009;53(4):352-367. doi:10.1007/s10384-009-0688-1

123. Ritter M, Hummer A, Ledolter AA, Holder GE, Windischberger C, Schmidt-Erfurth UM. Correspondence between retinotopic cortical mapping and conventional functional and morphological assessment of retinal disease. $\mathrm{Br} \mathrm{J}$ Ophthalmol. 2019;103(2):208-215. doi:10.1136/bjophthalmol-2017-311443

124. Ashtari M, Cyckowski LL, Monroe JF, et al. The human visual cortex responds to gene therapy-mediated recovery of retinal function. J Clin Invest. 2011;121(6):2160-2168. doi:10.1172/JCI57377

125. Farahbakhsh $\mathrm{M}$, Anderson EJ, Rider A, et al. A demonstration of cone function plasticity after gene therapy in achromatopsia. medRxiv. Published online 2020.

126. Soong GP, Lovie-Kitchin JE, Brown B. Does mobility performance of visually impaired adults improve immediately after orientation and mobility training? Optom Vis Sci Off Publ Am Acad Optom. 2001;78(9):657-666. doi:10.1097/00006324-200109000-00011

127. Long RG, Rieser JJ, Hill EW. Mobility in individuals with moderate visual impairments. J Vis Impair Blind. 1990;84(3):111-118.

128. Haymes S, Guest D, Heyes A, Johnston A. Mobility of people with retinitis pigmentosa as a function of vision and 
psychological variables. Optom Vis Sci Off Publ Am Acad Optom. 1996;73(10):621-637. doi:10.1097/00006324199610000-00001

129. Chung DC, McCague S, Yu Z-F, et al. Novel mobility test to assess functional vision in patients with inherited retinal dystrophies. Clin Experiment Ophthalmol. 2018;46(3):247-259. doi:10.1111/ceo.13022

130. Jacobson SG, Cideciyan A V, Ratnakaram R, et al. Gene therapy for leber congenital amaurosis caused by RPE65 mutations: safety and efficacy in 15 children and adults followed up to 3 years. Arch Ophthalmol (Chicago, III 1960). 2012;130(1):9-24. doi:10.1001/archophthalmol.2011.298

131. Russell S, Bennett J, Wellman JA, et al. Efficacy and safety of voretigene neparvovec (AAV2-hRPE65v2) in patients with RPE65-mediated inherited retinal dystrophy: a randomised, controlled, open-label, phase 3 trial. Lancet (London, England). 2017;390(10097):849-860. doi:10.1016/S0140-6736(17)31868-8

132. Marron JA, Bailey IL. Visual factors and orientation-mobility performance. Am J Optom Physiol Opt. 1982;59(5):413426. doi:10.1097/00006324-198205000-00009

133. Geruschat DR, Bittner AK, Dagnelie G. Orientation and mobility assessment in retinal prosthetic clinical trials. Optom Vis Sci Off Publ Am Acad Optom. 2012;89(9):1308-1315. doi:10.1097/OPX.0b013e3182686251

134. Kumaran N, Ali RR, Tyler NA, Bainbridge JWB, Michaelides M, Rubin GS. Validation of a Vision-Guided Mobility Assessment for RPE65-Associated Retinal Dystrophy. Trans/ Vis Sci Technol. 2020;9(10):5. doi:10.1167/tvst.9.10.5

135. Velikay-Parel $M$, Ivastinovic $D$, Koch $M$, et al. Repeated mobility testing for later artificial visual function evaluation. $J$ Neural Eng. 2007;4(1):S102-7. doi:10.1088/1741-2560/4/1/S12

136. Turano KA, Broman AT, Bandeen-Roche K, Munoz B, Rubin GS, West S. Association of visual field loss and mobility performance in older adults: Salisbury Eye Evaluation Study. Optom Vis Sci Off Publ Am Acad Optom. 2004;81(5):298-307. doi:10.1097/01.opx.0000134903.13651.8e 
137. Miraldi Utz V, Coussa RG, Antaki F, Traboulsi EI. Gene therapy for RPE65-related retinal disease. Ophthalmic Genet. 2018;39(6):671-677. doi:10.1080/13816810.2018.1533027

138. Milaneschi Y, Penninx BWJH. Depression in older persons with mobility limitations. Curr Pharm Des. 2014;20(19):3114-3118. doi:10.2174/13816128113196660060

139. Bennett CR, Bex PJ, Bauer CM, Merabet LB. The Assessment of Visual Function and Functional Vision. Semin Pediatr Neurol. 2019;31:30-40. doi:10.1016/j.spen.2019.05.006

140. Aleman TS, Miller AJ, Maguire KH, et al. A Virtual Reality Orientation and Mobility Test for Inherited Retinal Degenerations: Testing a Proof-of-Concept After Gene Therapy. Clin Ophthalmol. 2021;15:939-952. doi:10.2147/OPTH.S292527

141. Ahmed SF, McDermott KC, Burge WK, et al. Visual function, digital behavior and the vision performance index. Clin Ophthalmol. 2018;12:2553-2561. doi:10.2147/OPTH.S187131

142. Scott IU, Feuer WJ, Jacko JA. Impact of visual function on computer task accuracy and reaction time in a cohort of patients with age-related macular degeneration. Am J Ophthalmol. 2002;133(3):350-357. doi:10.1016/s00029394(01)01406-4

143. Daich Varela M, Esener B, Hashem S, Guimaraes T, Georgiou M, Michaelides M. Structural evaluation in inherited retinal diseases. Br J Ophthalmol. Published online 2021. 
Table 1: Summary of the most common methods used in clinic for IRD functional evaluation.

\begin{tabular}{|c|c|c|}
\hline Imaging Modality & Characteristics & Use in Inherited Retinal Disorders (IRD) \\
\hline $\begin{array}{l}\text { Best Corrected Visual } \\
\text { Acuity (BCVA) }\end{array}$ & $\begin{array}{l}\text { Usually, the first assessment in clinical practice, and the } \\
\text { most commonly performed. }\end{array}$ & $\begin{array}{l}\text { BCVA is a fundamental parameter with } \\
\text { significant correlation with Optical Coherence } \\
\text { Tomography (OCT) parameters, as well as with } \\
\text { visual field (VF). BCVA is an outcome measure } \\
\text { in several gene therapy trials. }\end{array}$ \\
\hline $\begin{array}{l}\text { Contrast } \\
\text { Sensitivity (CS) }\end{array}$ & $\begin{array}{l}\text { Multiple methods to assess CS are available, with the } \\
\text { Pelli-Robson charts being the most common. Newer } \\
\text { methods that test a wide range of spatial frequencies and } \\
\text { stimulus contrasts are increasingly being employed. }\end{array}$ & $\begin{array}{l}\text { CS is notably reduced in most IRD and has been } \\
\text { correlated with OCT features, retinal sensitivity } \\
\text { and reading speed. CS is a secondary outcome } \\
\text { measure in many gene therapy trials. }\end{array}$ \\
\hline Color Vision (CV) & $\begin{array}{l}\text { Colour can be assessed by a wide range of tests, } \\
\text { complex and simple, computer and paper-based, and } \\
\text { specifically tailored for visually impaired individuals. }\end{array}$ & $\begin{array}{l}\text { Particularly useful in specific differential } \\
\text { diagnoses such as discrimination between } \\
\text { complete and incomplete achromatopsia } \\
\text { (ACHM). Also, helpful to infer how cone systems } \\
\text { are affected and potentially measure differences } \\
\text { in specific cone response to intervention. }\end{array}$ \\
\hline $\begin{array}{l}\text { VF and } \\
\text { Sensitivity }\end{array}$ & $\begin{array}{l}\text { - Kinetic VF testing largely superseded by static perimetry. } \\
\text { - Octopus to a greater extent than Humphrey automated } \\
\text { static perimetry is better suited to the evaluation of retinal } \\
\text { sensitivity cross-sectionally and longitudinally in IRD. }\end{array}$ & $\begin{array}{l}\text { Evaluating VF and retinal sensitivity is key to } \\
\text { monitoring disease progression, as well as } \\
\text { impact of interventions. Recent advances include } \\
\text { modelling and Hill-of-Vision analysis software, }\end{array}$ \\
\hline
\end{tabular}




\begin{tabular}{|c|c|c|}
\hline & $\begin{array}{l}\text { - Microperimetry }=\text { fundus-guided perimetry allows } \\
\text { assessment of central macular sensitivity and improved } \\
\text { correlation between structure and function. Some } \\
\text { devices also have a range of testing conditions (photopic, } \\
\text { mesopic and scotopic) and dual-colour testing. }\end{array}$ & $\begin{array}{l}\text { from which topographic information and } \\
\text { volumetric assessments can be derived. } \\
\text { Testing under a range of conditions and 2-colour } \\
\text { microperimetry provides differential information } \\
\text { on rod, cone and mixed mechanisms, with a high } \\
\text { correlation with OCT parameters. } \\
\text { Static perimetry and microperimetry are very } \\
\text { common outcome measures in a wide range of } \\
\text { clinical trials. }\end{array}$ \\
\hline $\begin{array}{l}\text { Visual } \\
\text { Electrophysiology }\end{array}$ & $\begin{array}{l}\text { - Full-field (ff) electroretinogram (ERG): measures the } \\
\text { retinal electrical potential changes provoked by light } \\
\text { stimuli, under light and dark-adapted conditions. } \\
\text { - Multifocal (mf) ERG: measures retinal function in the } \\
\text { central macula and paramacula. } \\
\text {-Pattern ERG (PERG): typically uses a contrast-reversing } \\
\text { checkerboard stimulus to detect macular dysfunction. It } \\
\text { reflects the integrity of bipolar cells, retinal ganglion cells, } \\
\text { and macular photoreceptors. } \\
\text {-Electrooculogram (EOG): evaluates the RPE and the } \\
\text { photoreceptor-RPE complex. }\end{array}$ & $\begin{array}{l}\text { ffERG provides information on } \\
\text { generalised retinal function. } \\
\text { function. } \\
\text { PERG: assesses macular and optic nerve } \\
\text { function. } \\
\text { EOG: valuable in the diagnosis of } \\
\text { disorders of the RPE such as Best disease, } \\
\text { where a normal ffERG and abnormal EOG are } \\
\text { characteristic. } \\
\text { FST: provides information on which cell } \\
\text { type is primarily mediating the responses. First }\end{array}$ \\
\hline
\end{tabular}




\begin{tabular}{|l|l|l|}
\hline $\begin{array}{l}\text { Full-field light-sensitivity threshold (FST): provides a } \\
\text { psychophysical assessment of luminance thresholds } \\
\text { using white, blue, green and red full-field stimuli. }\end{array}$ & $\begin{array}{l}\text { developed for use in patients with profound } \\
\text { visual impairment unable to perform perimetry. } \\
\text { Has been shown to correlate with perimetry, } \\
\text { OCT parameters, BCVA, disease duration and } \\
\text { ffERG amplitude. It is a secondary outcome } \\
\text { measure in several gene therapy trials. }\end{array}$ \\
\hline
\end{tabular}

697

698

699

700

701

702

703

704

705

706

707

708

709

710 
Table 2: Summary of the current and developing methods for IRD functional evaluation used in research and clinical trial settings.

\begin{tabular}{|c|c|c|}
\hline Imaging Modality & Characteristics & Use in Inherited Retinal Disorders (IRD) \\
\hline $\begin{array}{l}\text { Low Luminance } \\
\text { Visual Acuity (LLVA) }\end{array}$ & $\begin{array}{l}\text { Can be measured by placing a filter over the patient's } \\
\text { best correction or over the letter chart, to simulate } \\
\text { mesopic conditions. }\end{array}$ & $\begin{array}{l}\text { Changes in LLVA are secondary outcome } \\
\text { measures in several IRD gene therapy trials. }\end{array}$ \\
\hline Dark adaptometry & $\begin{array}{l}\text { Yields insights into photoreceptor function, measuring } \\
\text { change in retinal sensitivity during transition from } \\
\text { photopic to scotopic conditions. }\end{array}$ & $\begin{array}{l}\text { Provides information on rod and cone kinetics } \\
\text { and thresholds - which are variably abnormal in } \\
\text { many IRD. }\end{array}$ \\
\hline $\begin{array}{l}\text { Photoaversion } \\
\text { Testing }\end{array}$ & $\begin{array}{l}\text { Both qualitative and quantitative assessment of light } \\
\text { discomfort and / or its associated impact on vision e.g. } \\
\text { BCVA and CS. Known as photosensitivity, photoaversion } \\
\text { and photophobia. }\end{array}$ & $\begin{array}{l}\text { Particularly useful in cone dysfunction } \\
\text { syndromes such as ACHM, and COD/CORD. } \\
\text { Currently a secondary/exploratory outcome } \\
\text { measure in gene therapy trials for ACHM. }\end{array}$ \\
\hline $\begin{array}{l}\text { Patient Reported } \\
\text { Outcome Measures }\end{array}$ & $\begin{array}{l}\text { General and disease-specific questionnaires designed to } \\
\text { better evaluate the impact of IRD on patients' lives. }\end{array}$ & $\begin{array}{l}\text { Invaluable instruments to help fully evaluate } \\
\text { treatment efficacy and calculate cost- } \\
\text { effectiveness. }\end{array}$ \\
\hline $\begin{array}{l}\text { Functional } \text { Magnetic } \\
\text { Resonance Imaging } \\
\text { (fMRI) }\end{array}$ & $\begin{array}{l}\text { Provides anatomical, physiological and functional } \\
\text { information in a single, non-interventional setting. }\end{array}$ & $\begin{array}{l}\text { fMRI has allowed the delineation of retinotopic } \\
\text { and population-receptive field maps; providing } \\
\text { objective visual function data and being currently } \\
\text { used to measure gene therapy outcomes. }\end{array}$ \\
\hline Vision-guided Mobility & $\begin{array}{l}\text { Mobility testing (MT) is a way of assessing functional } \\
\text { vision, which refers to the impact played by vision on }\end{array}$ & $\begin{array}{l}\text { MT is able to differentiate between controls and } \\
\text { patients and to capture longitudinal changes. It is }\end{array}$ \\
\hline
\end{tabular}




\begin{tabular}{|l|l|l|}
\hline & $\begin{array}{l}\text { everyday activities. It gives novel information on real- } \\
\text { world navigation. }\end{array}$ & $\begin{array}{l}\text { an important outcome measure in gene therapy } \\
\text { trials. }\end{array}$ \\
\hline $\begin{array}{l}\text { Virtual reality (VR) } \\
\text { and new trends }\end{array}$ & $\begin{array}{l}\text { VR represents a cost efficient and readily available } \\
\text { opportunity to capture aspects of functional vision under } \\
\text { real-life-like conditions. Tools and apps that assess our } \\
\text { vision while we use our own digital devices are also under } \\
\text { development. }\end{array}$ & $\begin{array}{l}\text { VPeasure of functional vision in individuals with } \\
\text { show-LCA. Apps potentially allow VF, tracking, } \\
\text { CV, CS and VA to be estimated whilst using } \\
\end{array}$ \\
\hline
\end{tabular}

